\title{
Where do negative stereotypes come from? The case of Indian English in the USA
}

\author{
Ethan Kutlu \& Caroline Wiltshire*
}

\begin{abstract}
Language attitudes inform social stereotyping, which in turn affects linguistic judgments (Fiske, Cuddy \& Glick 2007). Nonstandard varieties are particularly subject to negative stereotypes, being evaluated as "less friendly" and "hard to understand" (Giles \& Watson 2013). In this study, we investigate attitudes towards Indian English, a variety of English spoken by one of the largest immigrant populations in the USA (approximately 2.4 million), to understand the roots of linguistic stereotyping towards this variety of English. We compared attitudes of American English speakers towards Indian English and British English. Our results show that while American English speakers do not explicitly indicate any communication problem with Indian English, they disfavor Indian English compared to British English. This disfavoring of Indian English aligns with Raciolinguistic theories, suggesting that post-colonialism, especially Whiteness, is a factor in language prestige and how different varieties are perceived.
\end{abstract}

Keywords. raciolinguistics; World Englishes; Indian English; British English; language prestige; attitudes

1. Introduction. Indian English, an outer circle English variety, is spoken by over 125 million people (Government of India, 2011). Speakers of Indian English are exposed to this variety either from birth as simultaneous bilinguals or from early childhood as sequential bilinguals. Despite its widespread use, Indian English is perceived negatively by many monolingual speakers of English (Lindemann 2005). This necessitates more research to identify the forces creating negative stereotyping towards Indian English. Given that many Indian English speakers relocate to the West this negative linguistic stereotyping puts them at risk, pointing to a possible future public health issue (see Kim, Wang, Deng, Alvarez \& Li 2011). This study aims to observe attitudes towards Indian English speakers in the USA by conducting a survey which allows us to compare attitudes towards Indian English and British English with various explicit and implicit questions. We will first introduce the emergence of Indian English within the World Englishes framework. Then, we will talk about the linguistic features of Indian English, and finally, we will position Indian English within the Raciolinguistic framework. Following our discussion of Indian English, we will present our methodology and results. We will raise questions related to the implications of perceived negativity towards different varieties by referring to educational and workplace practices, and how Raciolinguistics can expand theories related to World Englishes.

2. Background. English was brought to India by the British Empire in the early 1600s, when Queen Elizabeth I sent rich merchants from London to start the East India Company (Schneider 2007). According to Schneider's analysis (2007), Indian English has already progressed through three stages since its beginnings and has now moved on to Stage 4. The first stage began in the

\footnotetext{
${ }^{*}$ We would like to thank Dr. Stefanie Wulff for her continuous support and our undergraduate research assistants Madison Forbis and Michael Bottini for their help with formatting the questionnaire. Special thanks to Dr. Vijay Ramjattan and LSA 2020 attendees for their invaluable feedback. Sincere thanks for Adriana Ojeda for providing enormous feedback without whom this project would not have been possible. Authors: Ethan Kutlu, University of Florida (denkutlu@ufl.edu) \& Caroline Wiltshire, University of Florida (wiltshir@ufl.edu).
} 
1600s and ended in 1757. During this period, British traders built up factories and trade-posts in different parts of India. These factories and trade-posts initiated language contact between English and many different Indian languages. By the end of the 1600s, there were English schools in India created by missionaries, leading to limited English bilingualism.

Many scholars, including Schneider, argue that Stage 2 of Indian English started somewhere in the mid-18th century (circa 1757). This was the time when the Battle of Plassey took place. The East India Company, created by the British, defeated the Nawab of Bengal which was the last independent province in India. This defeat changed the path of English in India as the language forced its way into politics and the economy. The East India Company was involved in all economic, political, and military decisions, and was supported by the Crown. This cultural infusion of the language eventually led English to be implemented in the school system, resulting in a rise of English bilinguals. Moreover, the Anglicist view emerged as victorious over the Orientalist view, as a result of the enormous English demand; knowing English helped one gain higher status in society, and English bilinguals earned better positions in India. Also, language contact between English and indigenous languages became more common. In Stage 2, English began to borrow vocabulary for the flora and fauna that the settlers did not have names for, such as mango, bungalow, bamboo, and curry. The existence of such borrowed vocabulary is one indication of Indian languages making their mark on the local version of English.

Since early 1900s, English has been in Stage 3 of its development. In other words, the Nativization of Indian English has since emerged in Indian society. There were many factors that triggered the onset and transition into Stage 3, including the Swadeshi movement, the decision by Bengal to leave, and finally, independence. Following India's independence and the choosing of English as the associate official language, India established its place in the Nativization period. The number of bilinguals has been increasing every year, and Indian English has become an incredibly widely used language, though more commonly so among the educated and elite. Also, different languages spoken in India each affected English in differing ways, giving rise to Indian English as an umbrella variety (including such varieties as Marathi English, Hindustani English, and Kannada English).

Currently, India is in a complex transition between Stages 3 and 4. There are signs of Endonormativization, as many English speakers in India acknowledge Indian English as their second language. There are more positive attitudes towards Indian English than any other South Asian varieties (Bernaisch \& Koch 2016). Indian English is now not as restricted to being used by the elite, and it is far more widespread though education systems, the media, and entertainment.

2.1. LINGUISTIC FEATURES OF INDIAN ENGLISH. As is observed in other varieties of English, Indian English also has its phonological, morphological, and structural features. Some of the most salient of Indian English's phonological features are the non-aspirated voiceless stops in onset position, the lack of interdental sounds such as $/ \theta /$ and /ð/, the retroflex feature on stop sounds, and a lack of reduction of unstressed vowels.

Morphologically, some features of Indian English are also saliently different from both American English and British English. These features include pluralization patterns, the progressive tense usage, and reduplication. In Indian English, plural morphemes can attach to mass nouns. For instance, words such as furniture or apparel can be pluralized as furnitures and apparels, respectively. Moreover, the progressive aspect marker '-ing' is used to indicate stative verbs; 
'I am knowing' is a common example of this process. Also, unlike in American English and British English, Indian English prefers to use reduplication to intensify meaning. For instance, 'Eat quickly!' can be uttered as 'Eat quick quick!'

There are also some differing structural features that can be observed in Indian English. Some of these features are known as invariant tag formation and no subject-auxiliary inversion in wh- questions. For instance, most of the tag formations are created by 'isn't it?' or 'no?' An example of this usage would mostly be 'You went to school, isn't it?' which, in "standard" American English and British English would be 'You went to school, didn't you?' Indian English also does not always use subject-auxiliary-inversion (SAI) in wh- constructions (Sailaja 2012), such as 'What you are doing?' as opposed to the standard in both American and British English, 'What are you doing?' (see Mesthrie 2019).

2.2. THE STATUS OF INDIAN ENGLISH IN DIFFERENT WORLD ENGLISHES MODELS. The area of World Englishes has been dominated by two models: Kachru's Three Circles Model (1992) and Schneider's Dynamic Model (2003). In both models, the status of Indian English has been discussed extensively. Kachru (1992) positioned Indian English in the outer circle since Indian English is spoken as a second language by many, along with different L1 Indian languages. Schneider (2003) reported Indian English to be moving towards Stage 4 and having particular Endonormative features. Individuals and communities of differing individual identity correspondingly identified with different kinds of South-Asian Englishes. The differences in attitudes towards these differing varieties was successfully tested in 2016 by Bernaisch and Koch. Their results showed that Indian English speakers perceive Indian English more positively than Sri Lankan English. This finding suggests that Indian English has passed the Nativization stage and has moved on to the Endonormative stage in which multiple varieties emerge and divergence occurs between these varieties. These identity variations and the emergence of the new dialects are also an indicator of increasingly rapid movement from Stage 4 to Stage 5, which is known as the Differentiation Stage.

While Schneider's theory followed a developmental model, Kachru's model foresaw the issues related to outer circle varieties through the lens of post-colonialism. The underlying assumption in Kachru's circles show that although English is one of the languages in many outer circle varieties as in inner circle varieties (Davydova 2012), these Englishes are not going to be equal to inner circle varieties. Importantly, one key issue with distinguishing varieties of Englishes is that speakers' backgrounds begin to define the status of the variety and vice-versa. For instance, although Caribbean English is an inner circle variety, it is not considered by many to be an appropriate or proper variety of English, and is often considered a 'broken' variety of English (Winford 1976).

Such linguistic discrimination targets minorities and/or vulnerable communities and causes stigmatization of these communities. Individuals from stigmatized variations of English who are singled out by speakers of non-stigmatized varieties tend to have depression earlier in life, perceiving themselves as lesser (Kim, Wang, Deng, Alvarez, \& Li 2011). The issue, however, is that linguistic stereotyping has less to do with the language spoken and more to do with who speaks the language.

2.3. RACIOLINGUISTICS AND WORLD ENGLISHES. The field of Raciolinguistics has emerged as a discussion and critique of issues related to the widespread preferences of whiteness in certain societies. For instance, Flores and Rosa (2015) discussed that language standardization observed in classrooms, especially where there are either bilinguals or English language learners, is mediated 
by raciolinguistic ideologies. These ideologies are shaped by the racialization of linguistic differences and systematic 'correction' of these features to standardize the language spoken, while minoritizing their speakers. Mostly, the authors argued that white privileges affect linguistic and cultural practices in the education setting.

One source of standardizing different varieties is Monolingualization or, as Silverstein (1996) describes it, a "culture of monoglot standardization." This practice of neutralizing speakers of different varieties of Englishes is also captured by Kachru's aforementioned outer circle definition. The rationale behind the Monolingualization of the varieties of Englishes is, however, far from linguistic practices. As Flores and Rosa (2015) discussed, Monolingualization has more to do with discriminating speakers of different languages or varieties than it does standardizing language. In other words, the stigmatized group is potentially going to be racially profiled and language is only going to be the mediator.

Ramjattan (2019), for instance, examined how through globalization, the demands to bring in English speakers to North America is facing racialized policies. The pursuit of having English speakers' accents erased through private accent reduction programs targeted mostly People of Color, where some bodies or identities are perceived as better or more skilled workers (Chand 2009). Ramjattan's work points out how certain varieties of Englishes can be stigmatized in work settings.

Indian English, which emerged after British colonization, is important to investigate from this point of view, as this variety originated from British English, which is stereotypically known as the most prestigious variety of English. American and Australian English, among others, also originated with British English, but Indian English is associated with non-white multilingual communities, then turns into a language of a minority. In the current research, we use Indian English and British English to measure American English speakers' attitudes towards Indian English. Our long-term goal is to adopt a Raciolinguistic perspective to investigate World Englishes and to further discuss the implications of racialized English varieties in education, policy, and workplace settings.

3. Method. We utilized an online questionnaire to measure the implicit and explicit attitudes towards American English, British English, and Indian English. The survey was published through the University of Florida's Qualtrics software (Qualtrics, Provo, UT). Fifty questions were created to measure participants' attitudes towards the different varieties as well as their comfort using their own varieties in their everyday and campus life. Participants were thanked after the completion of the survey. The survey was advertised to undergraduate and graduate students, faculty and staff in the Linguistics and Spanish and Portuguese departments as well as at the University of Florida's English Language Institute. We also advertised the survey through email, allowing us to collect additional data from more diverse origins. Once participants agreed to participate, they first filled out the demographic questions and answered the language related questions (e.g., whether they are bilingual, their age of acquisition etc.). For the experiment related questions, participants were given a statement and asked if they agree or disagree on a 9point Likert scale. We chose 9-point Likert scale to minimize the impact of participants' disfavoring of choosing extreme points. All datapoints were first exported from Qualtrics to Excel. We then use R's sjPlot function (created by Lüdecke 2019) to create our plots, and percentages.

3.1. PARTICIPANTS. 74 participants completed the survey. Out of the 74 participants, 59 participants completed more than half of the survey, which allow us to include $80 \%$ of our data. Further, of these 59 participants only $90.2 \%$ completed the survey fully. The mean age of the 
participants was 25.4 years old with a maximum age of 64 and a minimum age of 19 . Fifty-four participants were born and raised in the USA and five participants were born outside of the US. We had 44 participants who identified as cisgender women, 12 participants who identified as cisgender men, and three participants who did not want to disclose their gender identity. Regarding race and ethnicity, $33 \%$ of our participant group belonged to a non-white racial/ethnic background (see Table 1).

\begin{tabular}{cccc} 
Age & Gender Identity & Race and/or Ethnicity & Highest Degree \\
\hline Mean=25 years & $73 \%$ Cisgender woman & $64 \%$ White & $76 \%$ Undergraduate \\
Max $=64$ & $21 \%$ Cisgender man & $17 \%$ Biracial & $14 \%$ Master's Degree \\
Min=19 & $3 \%$ Not disclosed & $3 \%$ Hispanic & $10 \%$ PhD \\
& $1 \%$ Other & $3 \%$ South Asian &
\end{tabular}

Table 1. Demographic distribution

The lowest reported level of education was a high school degree. Moreover, $96 \%$ of our participants reported having a formal education in either a language other than their first language or a degree in Linguistics or Language Sciences.

4. Results. One goal of our survey was to see to what extent our participants were exposed to different varieties of Englishes, as our hypothesis was that lower exposure to Indian English might affect participants' judgments towards Indian English. Figure 1 shows the distribution of media exposure across all English varieties. The results show that compared to American English and British English, participants have the lowest exposure to Indian English in the media (approximately $2 \%$ ).

Exposure to Indian English



Exposure to British English

Figure 1. Percent exposure to different Englishes

Moreover, participants disagreed overall with the statements that Indian English is represented positively in media suggesting that a clear positive media exposure is lacking for Indian English (see below Figure 2). 


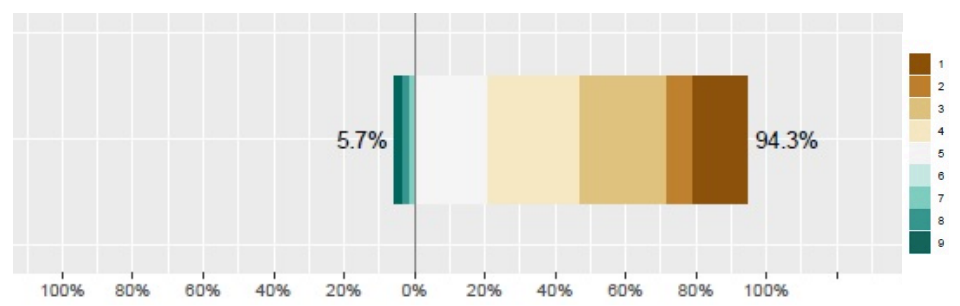

Figure 2. Indian English in the media

Participants were also asked explicitly if they perceive any linguistic discrimination towards Indian English speakers, and our results show that when asked explicitly about linguistic stereotyping towards Indian English, approximately $91.2 \%$ of our participants agree with the statement that there are negative stereotypes towards Indian English speakers. Moreover, when asked explicitly about treatment towards Indian English speakers, although remained mostly neutral, participants overall agreed with the statement "Indian English speakers earn less money in the USA." (see Figure 3).

Indian English speakers earn less money in the USA.

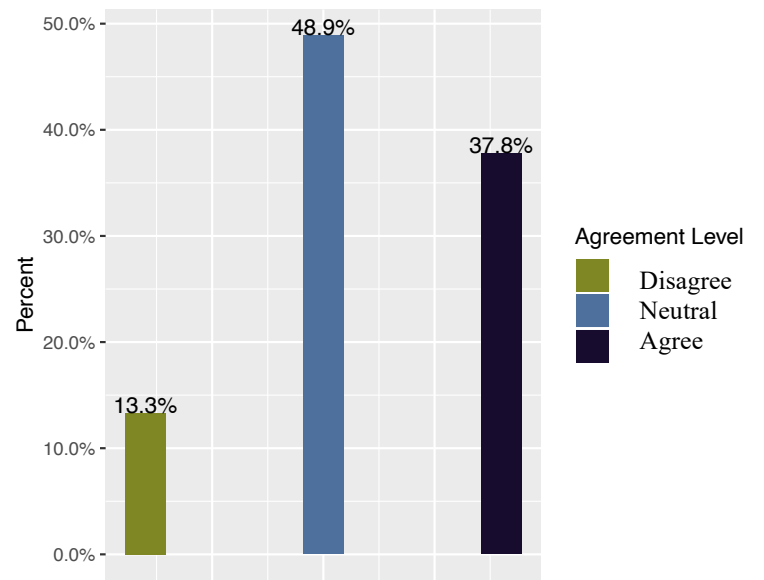

Figure 3. Percent agreement and disagreement of less income

Another finding was that participants tended to stay neutral regarding their preference of one variety over the other. However, this neutrality turns into disagreement when participants are asked about their preferences towards Indian English over British English. For instance, when asked explicitly about their preference of British English over Indian English, 32.3\% of participants preferred British English but, the majority reported either neutrality or disagreement (67.8\%). When we switched the preference direction to having a preference of Indian English over British English, agreement dropped from $32.3 \%$ to $3.5 \%$ with larger neutral response (40\%); disagreement or neutrality towards this question made up $96.8 \%$ of the responses. Our results suggest that although participants do not overtly indicate that they prefer British English over Indian English, they are more adamant that Indian English is not better than British English. This asymmetrical preference suggests a prejudice towards Indian English. When we asked explicitly about participants' preference of American English over Indian English, the majority of the responses were neutral. Furthermore, none of the participants preferred Indian English over American. Given that our sample was taken from participants in the USA, the strong preferences for American English is logical. However, the preference of British English over Indian English 
suggests that Indian English is not preferred by many American English speakers when compared to British English. (i.e., a prestigious variety, see Figure 4).

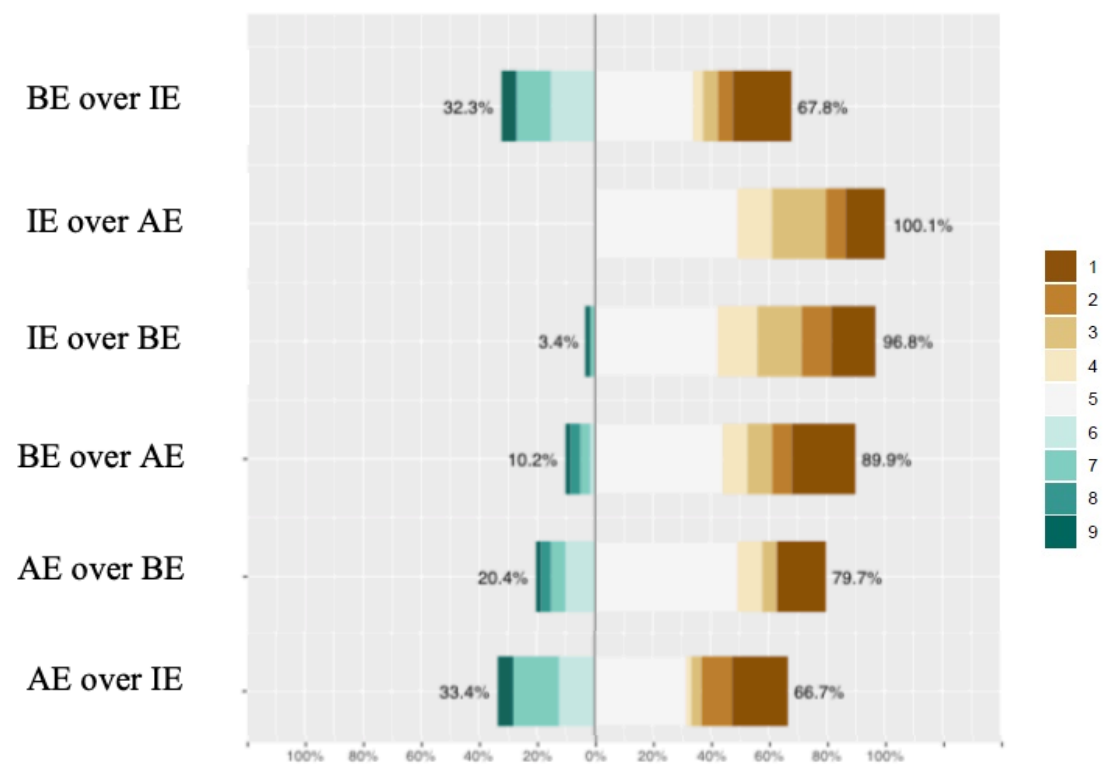

Figure 4. Preference of one variety over the other one (AE: American English, BE: British English, IE: Indian English)

5. Discussion and conclusion. In an ongoing online survey, we tested participants' preference of Indian English and British English explicitly and implicitly. Our results show that our participants were aware of linguistic discrimination towards Indian English. They also showed that participants had far more exposure to British English than to Indian English. Additionally, our results follow previous Raciolinguistic accounts on accent/variety perception in that they expose that linguistic discrimination and stigmatization go hand-in-hand with non-white populations. Although we did not ask questions related to race and ethnicity explicitly, we are observing tendencies towards favoring varieties largely attributed to white speakers compared to other races and ethnicities. More importantly, within the current World Englishes models, outer circle varieties are facing more prejudices due to post-colonialism and language power dynamics. Here, Indian English is a clear example of a variety that is affected by such ideologies. We argue that these ideologies could potentially affect listener judgments of accented speech as well as different English varieties. Moreover, consequences of negative exposure to certain varieties (mostly non-white speaker varieties of English) affect theory, policies, and language teaching. In our survey, we asked explicitly about the necessity for Indian English speakers to take TOEFL exams to prove their English proficiency. Most of our participants agreed or stayed neutral towards this question. Given the fact that most of our participants have had some exposure to Linguistics, it suggests that our understanding of post-colonial Englishes is still limited, and that we need better bilingual/bidialectal, multilingual/multidialectal as well as World Englishes theories and practices to account for varieties such as Indian English. For instance, our theories should acknowledge South Asian speakers of Indian English as native speakers, just like they are acknowledging British English speakers as native speakers of British English. Standardized testing policies and practices should also account for varieties of Englishes, and have the ability to test 
speakers' knowledge of particular varieties rather than focusing on a singular 'standardized' variety. Many standardization practices lead to discriminatory results for speakers of minoritized English varieties.

Crucially, being stigmatized in the social setting has many more widespread consequences. Given that many Indian English speakers reside in the USA, this ongoing social stigmatization is leading to a possible public health crisis. Additionally, our participants showed awareness of such stigmatization, yet also showed clear preferences for British and American English over Indian English. We argue that these preferences are mostly accommodated through media exposure. Overall, our results document stigmatization towards Indian English in the USA, and the emergency of having better theories, policies, and practices to protect Indian English as well as other bilingual or multilingual groups. One recent dissertation work by Ramjattan (2019), for instance, documented international teaching assistants' difficulty in adjusting their accent in Canada in order to be viewed effective workers.

In this research study, we compared three different varieties of Englishes: American, British, and Indian. Our comparison of these three varieties show that although American English speakers perceive negative stereotyping towards Indian English, and they agree that Indian English speakers are treated unfairly, they still prefer British English over Indian English. The overt preference or neutrality towards such statements when the direction is from British English towards Indian English suggest that Indian English is still perceived negatively even by those who are aware of the negative perception. We conclude that studies on Raciolinguistics are informative to argue for racial ideologies in World Englishes and how outer circle varieties are at risk. We invite linguistic studies to be more inclusive and consider the effects of racial profiling on linguistic discrimination. We also hope to shed light on educative practices where speakers of different varieties are overtly stigmatized.

\section{References}

Bernaisch, Tobias \& Christopher Koch. 2016. Attitudes towards Englishes in India. World Englishes 35(1). 118-132. https://doi.org/10.1111/weng.12174.

Chand, Vineeta. 2009. [v] at is going on? Local and global ideologies about Indian English. Language in Society 38(4). 393-419. https://doi.org/10.1017/S0047404509990200.

Davydova, Julia. 2012. Englishes in the Outer and Expanding Circles: A comparative study. World Englishes 31(3). 366-385. https://doi.org/10.1111/j.1467-971X.2012.01763.x.

Fiske, Susan T., Amy J.C. Cuddy \& Peter Glick. 2007. Universal dimensions of social cognition: Warmth and competence. Trends in Cognitive Sciences. 11(2). 77-83. https://doi.org/10.1016/j.tics.2006.11.005.

Flores, Nelson \& Jonathan Rosa. 2015. Undoing appropriateness: Raciolinguistic ideologies and language diversity in education. Harvard Educational Review 85(2). 149-171.

Giles, Howard \& Bernadette M. Watson. 2013. The social meanings of language, dialect and accent: International perspectives on speech styles. Language as Social Action. New York: Peter Lang Publishing.

Government of India. 2011. Census Results. Available online: http://www.censusindia.gov.in/2011-Common/CensusInfo.html. Accessed 18-11-2019.

Kachru, Braj. 1992. World Englishes: Approaches, issues and resources. Language Teaching 25(1). 1-14. https://doi.org/10.1017/S0261444800006583. 
Kim, Su Yeong, Yijie Wang, Shiying Deng, Rocio Alvarez \& Jing Li. 2011. Accent, perpetual foreigner stereotype, and perceived discrimination as indirect links between English proficiency and depressive symptoms in Chinese American adolescents. Developmental Psychology 47(1). 289-301. https://doi.org/10.1037/a0020712.

Lindemann, Stephanie. 2005. Who speaks “broken English"? US undergraduates' perceptions of non-native English. International Journal of Applied Linguistics 15(2). 187-212.

Lüdecke, Daniel. 2019. sjPlot: Data visualization for statistics in social science. https://doi.org/10.5281/zenodo.1308157. R package version 2.7.1. https://CRAN.Rproject.org/package $=$ sjPlot.

Mesthrie, Rajend. 2019. Contact linguistics and world Englishes. In Braj B. Kachru, Yamuna

Kachru \& Cecil L. Nelson (eds.),The handbook of world Englishes. 281-298. Oxford: Blackwell Publishing.

Ramjattan, Vijay A. 2019. Racializing the problem of and solution to foreign accent in business. Applied Linguistics Review. https://doi.org/10.1515/applirev-2019-0058.

Ramjattan, Vijay A. 2019. Working with an accent: The aesthetic labour of international teaching assistants in Ontario universities. Toronto, ON: The University of Toronto dissertation.

Sailaja, Pingali. 2012. Indian English: Features and sociolinguistic aspects. Language and Linguistics Compass 6(6). 359-370. https://doi.org/10.1002/lnc3.342.

Schneider, Edgar W. 2003. The dynamics of New Englishes: From identity construction to dialect birth. Language 79(2). 233-281. https://doi.org/10.1353/lan.2003.0136.

Schneider, Edgar W. 2007. Postcolonial English: Varieties around the world. Cambridge, UK: Cambridge University Press.

Silverstein, Michael. 1996. Monoglot "Standard" in America: Standardization and metaphors of linguistic hegemony. In Donald Lawrence Brenneis \& Ronald K.S. Macaulay (eds.), The Matrix of language: Contemporary linguistic anthropology. 284-306. Boulder, CO: Westview.

Qualtrics. (2019). Retrieved from https://www.qualtrics.com.

Wiebesiek, Lisa, Stephanie Rudwick \& Jochen Zeller. 2011. South African Indian English: A qualitative study of attitudes. World Englishes 30(2). 251-268. https://doi.org/10.1111/j.1467-971X.2011.01709.x.

Winford, Donald. 1976. Teacher attitudes toward language varieties in a creole community. International Journal of the Sociology of Language 8. 45-76. https://doi.org/10.1515/ ijsl.1976.8.45. 